\title{
BMJ open Cross-sectional study of sociodemographic patterning of risk factors for cardiovascular disease in three isolated-based subgroups of the Uyghur population in Xinjiang, China
}

Jingmei Jiang, ${ }^{1}$ Mayila Wufuer, ${ }^{2}$ Amuti Simayi, ${ }^{3}$ Muyesai Nijiati, ${ }^{3}$ Ming Fan, ${ }^{4}$ Pengcheng Zhu, ${ }^{2}$ Fenghui Chen, ${ }^{2}$ Guangliang Shan, ${ }^{1}$ Fang Xue, ${ }^{1}$ Xiaobing Tian, ${ }^{1}$ Feng Li, ${ }^{1}$ Lei Hou, ${ }^{1}$ Wei Han, ${ }^{1}$ Zuheng Cheng, ${ }^{2}$ Changchun Qiu ${ }^{1}$

To cite: Jiang J, Wufuer M, Simayi A, et al. Crosssectional study of sociodemographic patterning of risk factors for cardiovascular disease in three isolated-based subgroups of the Uyghur population in Xinjiang, China. BMJ Open 2013;3:e002279. doi:10.1136/bmjopen-2012002279

- Prepublication history for this paper are available online. To view these files please visit the journal online (http://dx.doi.org/10.1136/ bmjopen-2012-002279).

JJ, MW and AS contributed equally.

Received 29 October 2012 Revised 22 January 2013 Accepted 4 February 2013

This final article is available for use under the terms of the Creative Commons Attribution Non-Commercial 2.0 Licence; see http://bmjopen.bmj.com

For numbered affiliations see end of article.

\footnotetext{
Correspondence to Dr Zuheng Cheng; zuhengcheng@hotmail.com and Changchun Qiu; qiucc712@IBMS.pumc.edu. com
}

\section{ABSTRACT}

Objective: To explore the sociodemographic patterning of risk factors for cardiovascular disease (CVD) in three isolated-based subgroups of the Uyghur population in Xinjiang, China.

Design: A cross-sectional study. Between 2005 and 2008, a non-probability sampling design method was used to select three specific groups of the Uyghur rural populations based on their potential socioeconomic status (ie, isolated, semi-isolated and openenvironment status).

Setting: Three communities (named Desert, Turpan and Yuli Rob) in Southern Xinjiang autonomous region, China.

Participants: 1656 people were included in this study. The inclusion criteria were that all participants were 18 years or older, they were descendants of at least three generations living in the same region, and there was no history of intermarriage.

Main outcome measures: The prevalence of CVD risk factors (ie, tobacco use, alcohol use, obesity, dyslipidemia, hypertension, diabetes, etc) was assessed.

Results: Compared with the Desert and Turpan communities, Yuli Rob had the highest levels of obesity, dyslipidemia and hypertension, and the Desert had the lowest levels of CVD risk factors. Age standardisation slightly altered the estimates, though the patterns remained unchanged. Some unique characteristics were also found. For example, the Desert group displayed significantly lower high-density lipoprotein cholesterol (HDLC) level compared with Yuli Rob and Turpan groups. The mean values were 0.63 , 1.06 and $1.45 \mathrm{mmol} / \mathrm{l}$ for men and $0.64,1.22$ and $1.51 \mathrm{mmol} / \mathrm{l}$ for women $(p<0.0001)$. The HDLC levels in the Desert group increased with increase in body mass index and fasting glucose levels, which was inconsistent with previous studies.

Conclusions: Identifying the unique CVD risk factors of the ethnic-specific populations is very important in development of tailored strategies for the prevention of CVD.

\section{ARTICLE SUMMARY}

\section{Article focus}

- Cardiovascular disease (CVD) has been the leading cause of deaths in China since the last decade of the 20th century. The burden of risk factors for CVD is increasing, and this growth may be spreading to rural areas. However, most of the evidence comes from the Han populations, little is known about the risk factors for CVD in minority ethnic groups, especially in rural minority populations. In this study, we focus on exploring and comparing the sociodemographic patterning of CVD risk factors among three relatively isolated-based groups of the Uyghur rural population in Xinjiang China based on their potential socioeconomic status.

Key messages

- This is the first time a Chinese medical team has reached the hinterland of the Taklamakan Desert, the largest desert in China, to perform medical examinations and collect data on the health status of minorities of communities of Rob descent in China. We observed that the three subgroups, with different potential economic status, natural environment and lifestyle, also displayed unique distributions of some CVD risk factors. Our data indicate that epidemiological analyses in specific ethnic populations can identify unique CVD risk factors, and are likely to be very important in the development of tailored strategies for the prevention of CVD.

\section{INTRODUCTION}

Since the last decade of the 20th century, cardiovascular disease (CVD) has been the leading cause of death in China. ${ }^{1}{ }^{2}$ In 2003, it was estimated that 2.8 million CVD deaths occurred in China. ${ }^{3}$ The burden of CVD risk factors, such as elevated blood pressure (BP), cigarette smoking, hypercholesterolaemia, 


\section{ARTICLE SUMMARY}

Strengths and limitations of this study

- The strengths of this study are: (1) to provide firstly the valuable data and estimation of the distributions of the risk factors in these populations is vital for planning public health policies, because they have limited access to healthcare and can least afford to pay for the high treatment costs associated with chronic conditions; (2) unlike the epidemic of CVD in developed countries, which was driven mainly by urban migration, the current epidemic in developing countries may also be affected by increasing globalisation-greater interconnectedness of populations leading to a growing uniformity of lifestyles in both urban and rural areas. Unlike urban areas, the prevalence of risk factors for CVD in remote rural areas is less likely to be confounded by the effects of urban migration; and (3) such data may contribute to our understanding of disease aetiology, since comparison of the geographical distributions of prevalence of risk factors and diseases may allow the relative contributions of genes and the environment to be explored.

- There are some potential limitations to our study: (1) the nonprobability sampling design method and participation of less than half of those eligible, raises the possibility of selection bias; (2) simple categorisation of cholesterol as 'normal' or 'abnormal', BP as 'hypertensive' or 'normotensive' and FBG as 'diabetic' or 'non-diabetic', as in other studies. The risks associated with these and other factors operate on a continuum. Arbitrary categories tend to ignore the substantial risks contributed by these factors below the clinical threshold, that is, even within the so-called normal range; and (3) the problem of higher blood sugar levels compared with those of other studies. The reason for this needs further investigation.

excess body weight and diabetes, which are substantially influenced by behavioural, social, cultural and economic factors, is also increasing in China, and recent reports suggest that this trend may be spreading to rural areas. $^{2-5}$ However, most epidemiological studies have been performed in the Han population, ${ }^{6-10}$ which constitutes $92 \%$ of the population of mainland China, and little is known about the risk factors in minority ethnic groups, especially in minority rural populations.

The Xinjiang Autonomous Region is the largest province in China, accounting for one-sixth of the total area (figure 1), and had a population of 1955 million in 2003, according to the Xinjiang Bureau of Statistics survey data. Uyghurs are the major ethnic group, accounting for $45.2 \%$ of the total population compared with $40.6 \%$ of Han ethnicity, and $14.2 \%$ of other ethnic groups. In the vast rural area of Xinjiang, there are still some isolated or semi-isolated Uyghur communities with little communication with the outside world, and little economic development. Knowledge of the sociodemographic patterns of CVD risk factors among these populations is very important, not only to predict the future course of CVD for the planning of relevant policies for disease prevention and control, but also to provide new aetiological insights through their relationship with known variations in disease patterns.
In this study, three relatively geographically isolated subgroups of the Uyghur population (Desert, Yuli Rob and Turpan) were selected to explore and compare the sociodemographic patterns of CVD risk factors. We hypothesised that any variation in the effect of risk factors would be based on the environmental and lifestyle differences because of the genetic homogeneity of the different minorities.

\section{METHODS}

\section{Study participants}

Between 2005 and 2008, a non-probability sampling design method was used to select three specific groups of the Uyghur rural population among Uyghur residential areas concentrated in Southern Xinjiang based on their socioeconomic status (ie, isolated, semi-isolated and living in an open environment). The inclusion criteria were participants 18 years or older, who descended from at least three generations living in the same region, and who had no history of intermarriage. The groups included: (1) the Desert community: in the Daliyabuyi township where the Desert minority resides, sampled households were at least $10 \mathrm{~km}$ away from the main centre. The local government sent buses to transport participants from their houses to the township office for the medical examination, and 489 subjects (about $70 \%$ of adults) were recruited as our sample; (2) the Yuli Rob community: Karqvga, Dunkuotan and Akesupu townships of the Yuli Rob residential areas were selected as investigation sites. Before the medical examination, the local government broadcast information on the local radio station asking all eligible residents to attend the township office for a medical examination. Ultimately, 594 adults attended the medical examination (about $40 \%$ the region's Uyghur adults); and (3) the Turpan community: we selected Kageqiake village, located in the Turpan Depression about 50-60 m below sea level, as the investigation site. The total population of the village was 3045 , and $82 \%$ were Uyghurs. The same recruitment method was used as for the Yuli Rob people, and 573 subjects (about $32 \%$ of the Uyghur adults) were included.

\section{Measurements}

All medical examinations and interviews were carried out by clinical doctors and college students, respectively, from the research team. Written informed consent in the Uyghur language was obtained from all study participants prior to data collection and measurements. We confirmed that all applicable institutional and governmental regulations concerning the ethical issues related to human volunteers were followed for this study, which was approved by the Ethical Committees of Peking Union Medical College (PUMC) and Chinese Academy of Medical Sciences (CAMS).

\section{Epidemiological survey}

Interviewers administered a simple questionnaire to collect demographic and behavioural risk factor data. 


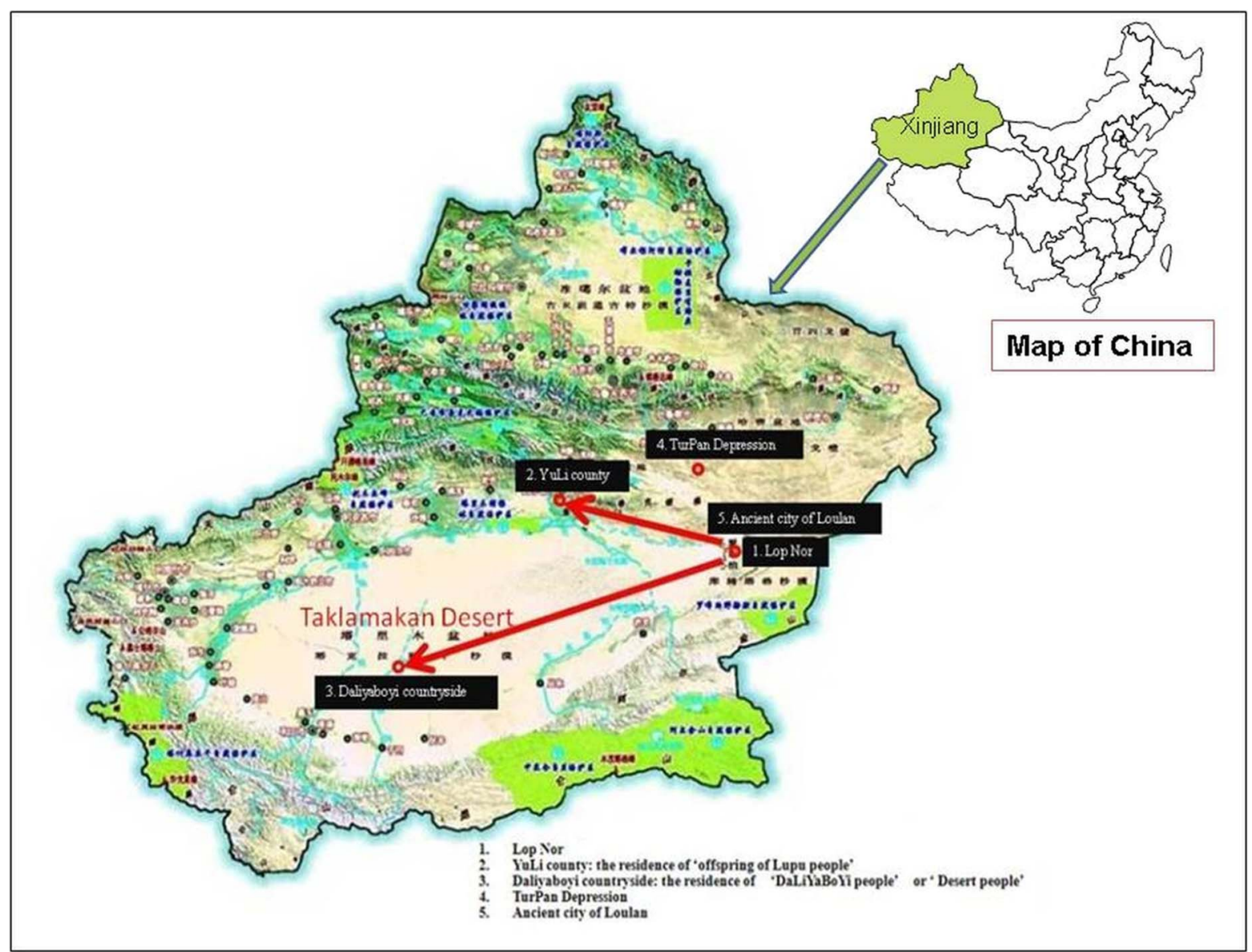

Figure 1 Xinjiang map: location of study areas in Xinjiang including Yuli county (Karqvga, Dunkuotan and Akesup townships), Daliyabuyi township and Turpan township (Kageqiake village).

Participants were asked about their current tobacco use (defined as at least one cigarette per day and lasting 1 year or more) in any form (cigarette or hand-rolled tobacco), and regular consumption of alcohol (irrespective of the amount). As this was the first time most participants had attended a medical examination, we concentrated on the subjects and did not collect information on their personal or family medical history.

The items in the medical examination included anthropometric parameters, heart and lung auscultation, electrocardiography measurement, BP measurement and laboratory tests. Anthropometric measurements were obtained by trained and certified staff using standard protocols. Sitting BP was measured twice with a mercury sphygmomanometer after a rest of at least $15 \mathrm{~min}$, and the mean of the two measurements was used.

Venous blood samples were taken after an overnight fast and centrifuged within $45 \mathrm{~min}$, stored in a portable refrigerator at $-20^{\circ} \mathrm{C}$, and transferred as soon as possible to the PUMC and CAMS for biochemical assays and genetic analysis. Serum high-density lipoprotein cholesterol (HDLC) was estimated directly by the elimination method, total cholesterol (TC) was estimated by an enzymatic end point method, triglycerides by the glycerol-3-phosphate oxidase-phenol-aminophenazone peroxidase (GPO-PAP) method, and glucose by the glucose oxidase-PAP (GOD-PAP) method.

\section{Statistical analysis}

Initially, the distribution of each risk factor was examined among the three isolated communities by age group and sex. We calculated the prevalence with 95\% CI for binary variables, and means with SD for continuous variables; we assessed trends in age by fitting a regression model for each outcome and performing the Wald test on model parameters; logistic regression was used for binary variables. Age-standardised prevalence for risk factors was calculated by the direct method with the use of data on the general Uyghur population distribution in Xinjiang (from the fifth census in Xinjiang, $2000^{11}$ ). All analyses were conducted with the use of SAS V.9.2 (Institute, Inc, Cary, North Carolina, USA). $\mathrm{p}<0.05$ was considered statistically significant.

\section{RESULTS}

All participants (1656) were farmers. Of them, 489 (29.5\%) were Desert, 594 (35.9\%) Yuli Rob and 573 (34.6\%) Turpan subjects. Overall, most adult subjects had not received any regular school education. Tobacco 
use was found only in $14.8 \%$ of Yuli Rob men and in 29.3\% of Turpan men, but, apart from a few Yuli Rob men $(2 \%)$, participants did not drink.

Table 1 shows the general characteristics of the subjects and the CVD risk factors by sex. We observed significantly different patterns among the three subgroups in anthropometric and risk factor measurements. Compared with the Desert group and the Turpan group, the Yuli Rob group was the oldest, tallest and heaviest, and had the greatest body mass index (BMI), systolic BP, diastolic BP and fasting blood glucose (FBG) levels. The Desert group had the lowest anthropometric parameters, and the lowest levels of the above risk factors. The Turpan group showed intermediate levels of risk factors (all $\mathrm{p}<0.0001$ ). However, when analysing the distribution of blood lipids, we observed that the HDLC levels of the Desert group were notably lower than that of Yuli Rob and Turpan group (mean value: 0.63, 1.06 and $1.45 \mathrm{mmol} / 1$ for men; $0.64,1.22$ and $1.51 \mathrm{mmol} / \mathrm{l}$ for women, $\mathrm{p}<0.0001$ ), which resulted in higher TC:HDLC ratios though their TC level was also low. In contrast, the Turpan people displayed a lower TC:HDLC ratio compared with the Desert group, with a higher TC level and a corresponding higher level of HDLC. The Yuli Rob people possessed the highest TC:HDLC ratios with the highest TC level and an intermediate HDLC level.

Table 2 shows the distribution of risk factors by age categories. The prevalence of most of the risk factors was higher in the middle-age groups ( $40-59$ years) compared with the younger group ( $<40$ years), although for some risk factors it seemed to decline in the older age group ( $\geq 60$ years), possibly owing to the small number of participants. However, the prevalence of hypertension showed a significantly increasing trend with age in the three subgroups. For example, for age categories $<40$, $40-59$ and $\geq 60$ years, the respective prevalence of hypertension was $5.7 \%, 16.7 \%$ and $29.4 \%$ in Desert men; $18.2 \%, 45.2 \%$ and $71.9 \%$ in Yuli Rob men; and $16.3 \%$, $22.0 \%$ and $49.1 \%$ in Turpan men. This trend was similar in women. In addition, apart from the Desert group who did not smoke, tobacco use was more common in the young group in Yuli Rob men, but in Turpan men, this trend was just the opposite, with more smokers in the older groups. Apart from Desert women, only a few of whom were $\geq 60$ years, which may have had some effect on the prevalence estimates, all results were obtained in large samples. Age-standardisation slightly altered the estimates of the prevalence of risk factors, but the overall trends were largely unchanged (figure 2).

Of all the risk factors for CVD, hypertension is the major cause of morbidity and mortality throughout China, and its influence is two-fold. It is a powerful predisposing factor for CVD, and its occurrence is also greatly influenced by other coexisting CVD risk factors. ${ }^{12-15}$ To explore this combined effect, we calculated the multivariable-adjusted ORs for hypertension in the three subgroups by sex (table 3). Overall, apart from age, obesity was a strong predictor of hypertension across all groups (except Desert group) and significantly increased the risk of hypertension independent of age in the Yuli Rob and Turpan groups. The ORs were 2.10 (95\% CI 1.07 to 4.09 ) and 7.11 (95\% CI 2.50 to 20.25), respectively, for Yuli Rob men and Turpan men, and were 2.04 (95\% CI 1.07 to 3.90$)$ and 3.92 (95\% CI, 1.94 to 7.92), respectively, for Yuli Rob women and Turpan women. A risk associated with high FBG was found only in Yuli Rob women and Turpan women (OR 1.30, 95\% CI 1.08 to 1.57 and OR $1.51,95 \%$ CI, 1.19 to 1.92 , respectively), and not in Yuli Rob and Turpan men. The TC:HDLC ratio and triglyceride level did not reveal an independent association with risk of hypertension among Yuli Rob and Turpan groups. It should be noted that in the Desert group, there was little evidence of an effect of any of the risk factors (except age) for hypertension.

\section{DISCUSSION}

This is the first time a Chinese medical team has reached the hinterland of the Taklamakan Desert to perform medical examinations and collect data on the health status of minorities of communities of Rob descent in China. The Desert community is a completely isolated subgroup of the Uyghur population living in the hinterland of the Taklamakan Desert, which is the largest desert in China. They were not known until 1989, when the Hotian area government found them and named the community the Daliyabuyi township, which was formally taken under Hotian government jurisdiction. The Yuli Rob community share a common ancestor with the Desert community, the Rob people. When the Lop Nur river dried up, the Rob people living in the surrounding area migrated and scattered afar, with the Desert group going south of Lop Nur, while the Yuli Rob group moved westward, migrated to Yuli county, and settled along the Tarim River shore (the biggest interior river in China). The Yuli Rob people have kept their traditional semi-isolated lifestyle, and one of the three survey sites still has no high roads or electricity. The third group included in the study was the Turpan minority, living in the Turpan Depression, the second lowest continental point in the world. Compared with the first two groups, the Turpan minority live in a more open environment, and mix with the Han population in the same village though they do not intermarry with the Han.

We observed that the three subgroups, with different economic statuses, natural environment and lifestyles, also displayed unique distributions of some CVD risk factors. First, there were almost no drinkers and only a small proportion of smokers in our subjects, which is different from the habits of most Uyghurs, indicating that the isolated communities have little interaction with the outside world. Second, there was a markedly lower level of HDLC in Desert subjects and a markedly higher level of HDLC in Turpan subjects, resulting in significantly 
Table 1 Characteristics of the participants and the distribution of risk factors for cardiovascular disease in three isolated groups of the Uyghur people by sex ${ }^{*}$

\begin{tabular}{|c|c|c|c|c|c|c|c|c|}
\hline & \multicolumn{3}{|l|}{ Men } & \multicolumn{3}{|l|}{ Women } & \multicolumn{2}{|l|}{ Total } \\
\hline & Desert $(n=293)$ & Yuli Rob (n=257) & Turpan $(n=239)$ & Desert $(n=196)$ & Yuli Rob $(n=337)$ & Turpan $(n=334)$ & Men (n=789) & Women $(n=867)$ \\
\hline Mean (SD), age (years) & $39.0(18.6)$ & $52.6(17.4)$ & $46.1(16.0)$ & 33.5 (12.0) & $47.9(16.0)$ & $45.2(13.6)$ & 45.5 (18.3) & $43.6(15.3)$ \\
\hline \multicolumn{9}{|l|}{ Age group (years) } \\
\hline $18-39$ & $176(60.1)$ & $66(25.7)$ & $86(36.0)$ & $134(68.4)$ & $114(33.8)$ & $119(35.6)$ & $328(41.6)$ & 367 (42.3) \\
\hline $40-59$ & $66(22.5)$ & $84(32.7)$ & $100(41.8)$ & $53(27.0)$ & $140(41.5)$ & $162(48.5)$ & $250(31.7)$ & $355(41.0)$ \\
\hline$\geq 60$ & $51(17.4)$ & 107 (41.6) & $53(22.2)$ & $9(4.6)$ & $83(24.6)$ & 53 (15.9) & 211 (26.7) & 145 (16.7) \\
\hline Mean (SD), height (cm) & $168.7(6.8)$ & $170.7(6.7)$ & $170.6(7.6)$ & $158.4(5.4)$ & $161.2(6.3)$ & $160.9(6.2)$ & $170.0(7.1)$ & $160.4(6.2)$ \\
\hline Mean (SD), weight (cm) & $60.4(7.8)$ & 77.7 (14.5) & $70.0(12.3)$ & $53.6(9.4)$ & 71.3 (13.6) & $65.8(12.1)$ & $68.9(13.7)$ & $65.2(13.9)$ \\
\hline \multicolumn{9}{|l|}{$\begin{array}{l}\text { Tobacco use in any } \\
\text { form }\end{array}$} \\
\hline Yes & $0(0.0)$ & $38(14.8)$ & $70(29.3)$ & $0(0.0)$ & $0(0.0)$ & $0(0.0)$ & $70(8.9)$ & $0(0.0)$ \\
\hline \multicolumn{9}{|l|}{ Alcohol used } \\
\hline Yes & $0(0.0)$ & $5(2.0)$ & $0(0.0)$ & $0(0.0)$ & $0(0.0)$ & $0(0.0)$ & $5(0.1)$ & $0(0.0)$ \\
\hline Mean (SD), BMI $\left(\mathrm{kg} / \mathrm{m}^{2}\right)$ & $21.2(2.4)$ & $26.6(4.8)$ & $24.0(3.8)$ & $21.4(3.7)$ & $27.5(4.9)$ & $25.4(4.6)$ & $23.8(4.4)$ & $25.3(5.1)$ \\
\hline $\begin{array}{l}\text { Median (IQR), TG } \\
(\mathrm{mmol} / \mathrm{l})\end{array}$ & $0.75(0.73-0.90)$ & $1.41(0.97-2.16)$ & $0.89(0.66-1.15)$ & $0.75(0.56-0.82)$ & $1.29(0.83-1.76)$ & $0.95(0.67-1.30)$ & $0.91(0.75-1.39)$ & $0.95(0.70-1.46)$ \\
\hline $\begin{array}{l}\text { Mean (SD), HDLC } \\
(\mathrm{mmol} / \mathrm{l})\end{array}$ & $0.63(0.24)$ & $1.06(0.20)$ & $1.45(0.23)$ & $0.64(0.31)$ & $1.22(0.25)$ & $1.51(0.24)$ & $1.02(0.40)$ & $1.20(0.42)$ \\
\hline Mean (SD), TC (mmol/l) & $1.78(0.55)$ & $4.54(0.90)$ & $4.27(0.78)$ & $1.74(0.70)$ & $4.70(0.96)$ & $4.44(0.86)$ & $3.43(1.48)$ & $3.93(1.47)$ \\
\hline TC:HDLC ratio & $3.19(1.87)$ & $4.40(1.05)$ & $3.01(0.61)$ & $3.04(1.52)$ & $3.96(0.92)$ & $3.00(0.67)$ & $3.53(1.46)$ & $3.38(1.11)$ \\
\hline $\begin{array}{l}\text { Mean (SD) SBP } \\
(\mathrm{mm} \mathrm{Hg})\end{array}$ & $110.8(17.9)$ & $134.4(22.0)$ & $117.7(19.1)$ & $108.8(18.9)$ & $135.1(25.7)$ & $117.5(24.4)$ & $120.6(22.0)$ & $122.4(26.1)$ \\
\hline $\begin{array}{l}\text { Mean (SD), DBP } \\
(\mathrm{mm} \mathrm{Hg})\end{array}$ & $72.9(11.3)$ & $84.9(13.1)$ & $76.6(12.9)$ & $72.3(11.4)$ & $85.2(14.9)$ & $76.2(14.6)$ & $77.9(13.4)$ & $78.8(14.8)$ \\
\hline $\begin{array}{l}\text { Median (IQR), FBG } \\
(\mathrm{mmol} / \mathrm{l})\end{array}$ & $4.9(4.6-5.4)$ & $6.2(5.6-7.0)$ & $6.0(5.5-6.4)$ & $4.9(4.6-5.6$ & $6.2(5.7-7.0)$ & $6.1(5.7-6.5)$ & $5.7(4.9-6.4)$ & $6.0(5.4-6.7)$ \\
\hline
\end{tabular}

${ }^{*}$ Values are numbers (percentage) of participants unless stated otherwise.

BMI, body mass index $\left(\mathrm{kg} / \mathrm{m}^{2}\right)$; DBP, diastolic blood pressure; FBG, fasting blood glucose; HDLC, high-density lipoprotein cholesterol; IQR, interquartile range; SBP, systolic blood pressure; $\mathrm{BMI}$, body mass index $\left(\mathrm{kg} / \mathrm{m}^{2}\right)$; DBP, $\mathrm{D}$ TC, total cholesterol; TG, triglyceride.
TCl 
Table 2 Age-specific prevalence of risk factors for cardiovascular disease in three subgroups of the Uyghur people by sex

\begin{tabular}{|c|c|c|c|c|c|c|c|c|c|c|c|c|}
\hline & \multicolumn{4}{|l|}{ Desert group } & \multicolumn{4}{|l|}{ Yuli Rob group } & \multicolumn{4}{|l|}{ Turpan group } \\
\hline & $18-39(n=176)$ & $40-59(n=66)$ & $\geq 60(n=51)$ & p Value & $18-39(n=66)$ & $40-59(n=84)$ & $\geq 60(n=107)$ & p Value & $18-39(n=86)$ & $40-59(n=100)$ & $\geq 60(n=60)$ & $\overline{p \text { Value }}$ \\
\hline \multicolumn{13}{|l|}{ Men } \\
\hline Smoke & 0.0 & 0.0 & 0.0 & - & $\begin{array}{l}47.0 \\
(41.0-65.1)\end{array}$ & $\begin{array}{l}19.1 \\
(10.7-27.4)\end{array}$ & $\begin{array}{l}1.9 \\
(0.0-4.4)\end{array}$ & $<0.001$ & $\begin{array}{l}23.3 \\
(14.3-32.2)\end{array}$ & $\begin{array}{l}33.0 \\
(23.8-42.2)\end{array}$ & $\begin{array}{l}32.1 \\
(19.6-46.3)\end{array}$ & 0.0979 \\
\hline Overweight* & $\begin{array}{l}2.8 \\
(0.3-5.3)\end{array}$ & $\begin{array}{l}4.6 \\
(0.0-9.6)\end{array}$ & $\begin{array}{l}9.8 \\
(1.6-17.9)\end{array}$ & 0.2218 & $\begin{array}{l}37.9 \\
(26.2-49.6)\end{array}$ & $\begin{array}{l}35.7 \\
(25.5-46.0)\end{array}$ & $\begin{array}{l}33.6 \\
(24.7-42.6)\end{array}$ & 0.2377 & $\begin{array}{l}20.9 \\
(12.3-29.5)\end{array}$ & $\begin{array}{l}35.0 \\
(25.7-44.4)\end{array}$ & $\begin{array}{l}17.0 \\
(6.9-27.1)\end{array}$ & 0.8162 \\
\hline Obesity† & $\begin{array}{l}0.6 \\
(0.0-1.7)\end{array}$ & $\begin{array}{l}1.5 \\
(0.0-4.7)\end{array}$ & $\begin{array}{l}2.0 \\
(0.0-5.8)\end{array}$ & 0.0636 & $\begin{array}{l}9.1 \\
(2.2-16.0)\end{array}$ & $\begin{array}{l}28.6 \\
(18.9-38.2)\end{array}$ & $\begin{array}{l}24.3 \\
(16.2-32.4)\end{array}$ & 0.4659 & $\begin{array}{l}4.7 \\
(0.2-9.1)\end{array}$ & $\begin{array}{l}11.0 \\
(4.9-17.1)\end{array}$ & $\begin{array}{l}9.4 \\
(1.6-17.3)\end{array}$ & 0.2650 \\
\hline Total:HDLC ratio & $\begin{array}{l}13.1 \\
(8.1-18.1)\end{array}$ & $\begin{array}{l}7.6 \\
(1.2-14.0)\end{array}$ & $\begin{array}{l}15.7 \\
(5.7-25.7)\end{array}$ & 0.9337 & $\begin{array}{l}30.3 \\
(19.2-41.4)\end{array}$ & $\begin{array}{l}46.4 \\
(35.8-57.1)\end{array}$ & $\begin{array}{l}33.6 \\
(24.7-42.6)\end{array}$ & 0.8922 & $\begin{array}{l}0.0 \\
(0.0-0.0)\end{array}$ & $\begin{array}{l}4.0 \\
(0.2-7.8)\end{array}$ & $\begin{array}{l}1.9 \\
(0.2-5.6)\end{array}$ & 0.3188 \\
\hline $\mathrm{TG} \geq 1.69 \mathrm{mmol} / \mathrm{l}$ & $\begin{array}{l}4.6 \\
(1.5-7.6)\end{array}$ & $\begin{array}{l}9.1 \\
(2.0-16.0)\end{array}$ & $\begin{array}{l}7.8 \\
(0.5-15.2)\end{array}$ & 0.6578 & $\begin{array}{l}39.4 \\
(27.6-51.2)\end{array}$ & $\begin{array}{l}41.7 \\
(31.1-52.2)\end{array}$ & $\begin{array}{l}32.7 \\
(23.8-41.6)\end{array}$ & 0.3122 & $\begin{array}{l}10.5 \\
(4.0-16.9)\end{array}$ & $\begin{array}{l}13.0 \\
(6.4-19.6)\end{array}$ & $\begin{array}{l}5.7 \\
(0.0-11.9)\end{array}$ & 0.4738 \\
\hline Hypertension & $\begin{array}{l}5.7 \\
(2.3-9.1)\end{array}$ & $\begin{array}{l}16.7 \\
(7.7-25.7)\end{array}$ & $\begin{array}{l}29.4 \\
(16.9-41.9)\end{array}$ & $<0.0001$ & $\begin{array}{l}18.2 \\
(8.9-27.5)\end{array}$ & $\begin{array}{l}45.2 \\
(34.6-55.9)\end{array}$ & $\begin{array}{l}71.9 \\
(63.5-80.2)\end{array}$ & $<0.0001$ & $\begin{array}{l}16.3 \\
(8.5-24.1)\end{array}$ & $\begin{array}{l}22.0 \\
(13.9-31.1)\end{array}$ & $\begin{array}{l}49.1 \\
(35.6-62.5)\end{array}$ & $<0.0001$ \\
\hline Diabetesł & $\begin{array}{l}11.4 \\
(6.7-16.1)\end{array}$ & $\begin{array}{l}12.1 \\
(4.3-20.0)\end{array}$ & $\begin{array}{l}11.8 \\
(2.9-20.6)\end{array}$ & 0.9047 & $\begin{array}{l}15.2 \\
(6.5-23.8)\end{array}$ & $\begin{array}{l}27.4 \\
(17.9-36.9)\end{array}$ & $\begin{array}{l}31.8 \\
(23.0-40.6)\end{array}$ & 0.0200 & $\begin{array}{l}7.0 \\
(1.6-12.4)\end{array}$ & $\begin{array}{l}13.0 \\
(6.4-19.6)\end{array}$ & $\begin{array}{l}18.9 \\
(8.3-29.4)\end{array}$ & 0.0375 \\
\hline Women & $n=134$ & $n=53$ & $n=9$ & & $n=114$ & $n=140$ & $\mathrm{n}=83$ & & $n=119$ & $\mathrm{n}=162$ & $n=53$ & \\
\hline Overweight & $\begin{array}{l}8.2 \\
(3.6-12.9)\end{array}$ & $\begin{array}{l}11.3 \\
(2.8-19.9)\end{array}$ & $\begin{array}{l}22.2 \\
(0.0-49.4)\end{array}$ & 0.0376 & $\begin{array}{l}50.0 \\
(40.8-59.2)\end{array}$ & $\begin{array}{l}13.6 \\
(7.9-19.2)\end{array}$ & $\begin{array}{l}37.4 \\
(26.9-47.81)\end{array}$ & 0.0134 & $\begin{array}{l}26.9 \\
(18.9-34.9)\end{array}$ & $\begin{array}{l}40.1 \\
(32.6-47.7)\end{array}$ & $\begin{array}{l}47.2 \\
(33.7-60.6)\end{array}$ & $<0.0016$ \\
\hline Obesity & $\begin{array}{l}3.0 \\
(0.0-5.9)\end{array}$ & $\begin{array}{l}7.6 \\
(0.4-14.7)\end{array}$ & 0.0 & 0.9723 & $\begin{array}{l}14.0 \\
(7.7-20.4)\end{array}$ & $\begin{array}{l}37.1 \\
(29.1-45.2)\end{array}$ & $\begin{array}{l}25.3 \\
(16.0-34.7)\end{array}$ & 0.0872 & $\begin{array}{l}5.0 \\
(1.1-9.0)\end{array}$ & $\begin{array}{l}20.4 \\
(14.2-26.6)\end{array}$ & $\begin{array}{l}20.8 \\
(9.3-31.7)\end{array}$ & 0.0103 \\
\hline Total:HDLC ratio & $\begin{array}{l}11.9 \\
(6.5-17.4)\end{array}$ & $\begin{array}{l}18.9 \\
(8.3-29.4)\end{array}$ & $\begin{array}{l}22.2 \\
(0.0-49.4)\end{array}$ & 0.1704 & $\begin{array}{l}12.3 \\
(6.3-18.3)\end{array}$ & $\begin{array}{l}31.4 \\
(23.7-39.1)\end{array}$ & $\begin{array}{l}33.7 \\
(23.6-43.9)\end{array}$ & $<0.0001$ & $\begin{array}{l}0.0 \\
(0.0-0.0)\end{array}$ & $\begin{array}{l}4.3 \\
(1.2-7.5)\end{array}$ & $\begin{array}{l}7.6 \\
(0.4-14.7)\end{array}$ & 0.0096 \\
\hline $\mathrm{TG} \geq 1.69 \mathrm{mmol} / \mathrm{l}$ & $\begin{array}{l}3.7 \\
(0.5-6.9)\end{array}$ & $\begin{array}{l}7.6 \\
(0.4-14.7)\end{array}$ & 0.0 & 0.6578 & $\begin{array}{l}12.3 \\
(6.3-18.3)\end{array}$ & $\begin{array}{l}36.4 \\
(28.5-44.4)\end{array}$ & $\begin{array}{l}31.3 \\
(21.4-41.3)\end{array}$ & 0.0012 & $\begin{array}{l}4.2 \\
(0.6-7.8)\end{array}$ & $\begin{array}{l}15.4 \\
(9.9-21.0)\end{array}$ & $\begin{array}{l}24.5 \\
(12.9-36.1)\end{array}$ & $<0.0001$ \\
\hline Hypertension & $\begin{array}{l}5.2 \\
(1.5-9.0)\end{array}$ & $\begin{array}{l}11.3 \\
(2.8-19.9)\end{array}$ & $\begin{array}{l}55.6 \\
(23.1-88.0)\end{array}$ & 0.0002 & $\begin{array}{l}17.5 \\
(10.6-24.5)\end{array}$ & $\begin{array}{l}60.7 \\
(52.6-68.8)\end{array}$ & $\begin{array}{l}69.9 \\
(60.1-79.8)\end{array}$ & $<.0001$ & $\begin{array}{l}10.1 \\
(4.7-15.5)\end{array}$ & $\begin{array}{l}32.7 \\
(25.5-39.9)\end{array}$ & $\begin{array}{l}50.9 \\
(37.5-64.4)\end{array}$ & $<0.0001$ \\
\hline Diabetes & $\begin{array}{l}16.4 \\
(10.2-22.7)\end{array}$ & $\begin{array}{l}17.0 \\
(6.9-27.1)\end{array}$ & 0.0 & 0.4445 & $\begin{array}{l}16.7 \\
(9.8-23.5)\end{array}$ & $\begin{array}{l}33.6 \\
(25.8-41.4)\end{array}$ & $\begin{array}{l}25.3 \\
(16.0-34.7)\end{array}$ & .1021 & $\begin{array}{l}5.1 \\
(1.1-9.0)\end{array}$ & $\begin{array}{l}13.0 \\
(7.8-18.1)\end{array}$ & $\begin{array}{l}32.1 \\
(19.5-44.6)\end{array}$ & $<0.0001$ \\
\hline
\end{tabular}

HDLC, high-density lipoprotein cholesterol; TG, triglyceride.

*indicates $\mathrm{BMI} \geq 25$ and $<28\left(\mathrm{~kg} / \mathrm{m}^{2}\right)$.

tindicates $\mathrm{BMI} \geq 28\left(\mathrm{~kg} / \mathrm{m}^{2}\right)$.

fdiabetes (fasting blood glucose (FBG) concentration $\geq 7.0 \mathrm{mmol} / \mathrm{l}$ ). 

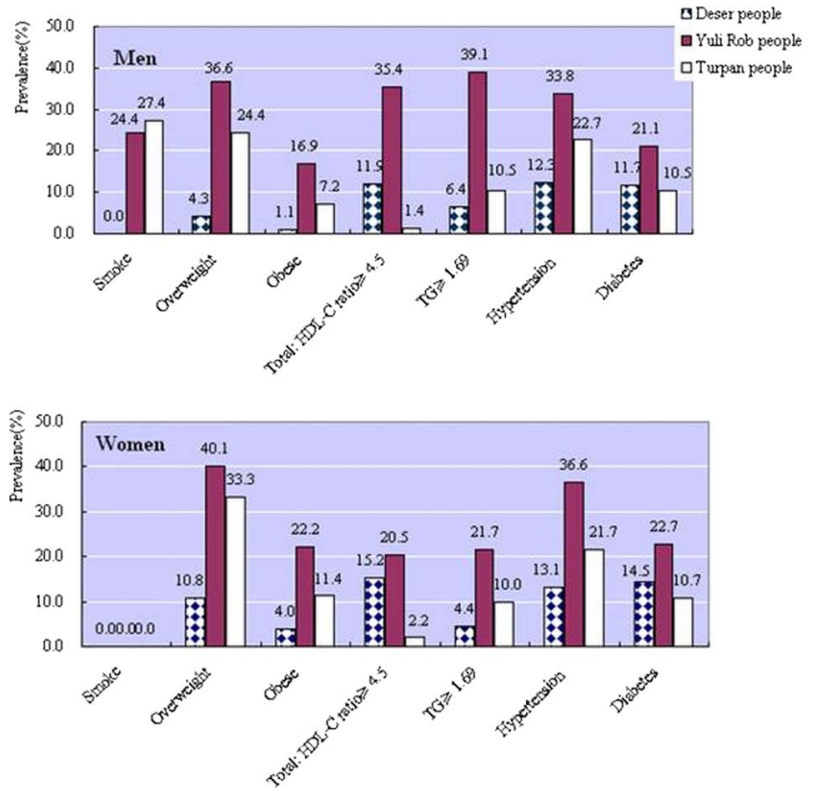

Figure 2 Age-standardised prevalence of risk factors for cardiovascular disease in three subgroups of the Uyghur population by sex.

different patterns of the TC:HDLC ratio, which is commonly used as a predictor of cardiovascular incidents and death, ${ }^{16}{ }^{17}$ suggesting different possibilities for the role of HDLC in the elevated risk of CVD in the two subgroups. Third, unlike other studies wherein a reduction in HDLC levels was commonly observed in subjects in the Chinese Han population who had features of metabolic syndrome (eg, high blood pressure, obesity, diabetes, etc), ${ }^{18}{ }^{19}$ the Desert group showed a different relationship between HDLC levels and BMI and serum FBG levels. For BMI $<25,25-29$ and $\geq 30.0 \mathrm{~kg} / \mathrm{m}^{2}$, the mean HDLC was $0.63,0.61$ and $0.74 \mathrm{mmol} / \mathrm{l}$, respectively, in the Desert group ( $p=0.3489$ ). For serum FBG $<7.0$ and $\geq 7.0 \mathrm{mmol} / 1$, the mean HDLC was 0.75 and $0.61 \mathrm{mmol} / 1$, respectively, in the Desert group $(\mathrm{p}<0.0001)$. This trend was opposite to that in other studies and was also found in another study conducted in a rural Uyghur population in the Hetian area. The reason for the difference is yet to be determined. ${ }^{20}$ Finally, Yuli Rob subjects possessed a higher prevalence of overweight or obesity and hypertension compared with Desert and Turpan subjects. For example, 38.3\% of the Yuli Rob subjects with BMI in the normal range (BMI $<25 \mathrm{~kg} / \mathrm{m}^{2}$ ) suffered from hypertension, which was 2.5-fold and 3.6-fold higher than Turpan and Dessert subjects, respectively. Moreover, we also observed that hypertension in the Yuli Rob population was more common in the younger group (age $<40$ years) compared with that of the two older groups, indicating that other factors, other than age and BMI, may contribute to the high prevalence of hypertension in this subgroup.

Some issues are worthy of discussion according to the observed intergroup differences in the CVD risk factor profile. First, there are unique dietary differences: for

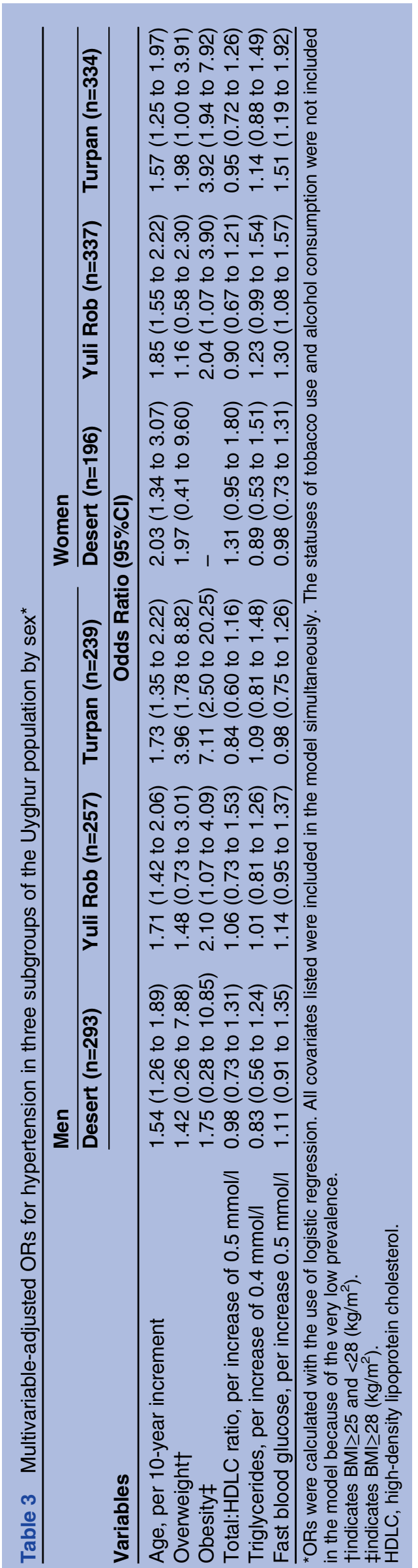


generations the Desert people, living in the hinterland of the Taklamakan Desert, have had no choice in their lifestyle, with animal husbandry providing a living. They face adverse conditions with limited nutritional resources, lack of fruits and vegetables and little carbohydrates, resulting in low body weight, low serum lipid profiles and a low prevalence of hypertension. In contrast, the Yuli Rob people in the fertile Tarim River area fish and farm for a living, with their diet including more pasta and meat. They had higher levels of lipid risk factors, overweight and a higher prevalence of hypertension. The Turpan people live in a more open environment, and the area is famous for grape production. Therefore, besides a normal diet like the Yuli Rob people, the Turpan people had more fruit consumption. Thus, although there was a high prevalence of overweight, which is a characteristic of subjects of Uyghur origin, they had a much lower prevalence of high TC: HDLC ratios and hypertension compared with that of Yuli Rob subjects. These variations are also illustrated by another study of $\mathrm{Yi}$ minority ethnic migrant groups in south China, where environmental changes from altered lifestyles are superimposed on genetic influences. ${ }^{17}$ Second, the environmental conditions differed widely across three subgroups. The Yuli Rob population is located about $2000 \mathrm{~m}$ above sea level, while Desert and Turpan populations live in extremely hot climates. As temperature decreases about $1^{\circ} \mathrm{C}$ for each $150 \mathrm{~m}$ increase in altitude, at $2000 \mathrm{~m}$ the temperature is roughly $14^{\circ} \mathrm{C}$ lower than that at sea level. Some studies reported that chronic exposure to hypobaric hypoxia at a median altitude increases parasympathetic and sympathetic tone in healthy subjects, and is significantly associated with an increase in $\mathrm{BP}^{21}{ }^{22}$ while other studies suggested that after years of residence at high altitude, BP may actually be lower than that observed among residents at sea level. ${ }^{23}$ Our data showed more hypertension in Yuli Rob subjects at a younger age and in those with BMI in the normal range, but whether this elevation in $\mathrm{BP}$ has some relationship with altitude needs further investigation. Furthermore, there was no evidence from previous studies ${ }^{24-26}$ that hot, dry climates may have an effect on BP in healthy subjects, suggesting that when the same gene pool is confronted with different environments, the conventional risk factors play a major role. The challenge of preventing CVD diseases lies in identifying and addressing the components most relevant to each community at their present and projected levels of CVD risk.

An assessment of the pattern of risk factors for CVD in rural minority populations is important for several reasons. First, despite rapid urbanisation in China, most Chinese minority populations still live in rural areas and, as with any Han rural population, they have limited access to healthcare and can least afford to pay for the high treatment costs associated with chronic conditions, especially those who live in remote and isolated areas. Estimation of the distributions of the risk factors in these populations is vital for planning public health policies. Second, unlike the epidemic of CVD in developed countries, which was driven mainly by urban migration, the current epidemic in developing countries may also be affected by increasing globalisation-greater interconnectedness of populations leading to a growing uniformity of lifestyles in both urban and rural areas. ${ }^{27-29}$ Unlike urban areas, the prevalence of risk factors for CVD in remote rural areas is less likely to be confounded by the effects of urban migration. Third, such data may contribute to our understanding of disease aetiology, since comparison of the geographical distributions of the prevalence of risk factors and diseases may allow the relative contributions of genes and the environment to be explored. ${ }^{27}$

There are some potential limitations in our study: (1) in the specific natural environment, we were unable to implement random sampling, therefore the nonprobability sampling design method and participation of less than half of those eligible raises the possibility of selection bias; (2) there was simple categorisation of cholesterol as 'normal' or 'abnormal', BP as 'hypertensive' or 'normotensive', and FBG as 'diabetic' or 'nondiabetic', as in other studies. The risks associated with these and other factors operate on a continuum. Limited categories tend to ignore the substantial risks contributed by these factors below the clinical threshold, that is, even within the so-called normal range ${ }^{30}{ }^{31}$; (3) because this is the first examination of isolated populations and semi-isolated populations, there were no data available on the personal medical history of the participants, which might result in misclassification of hypertension and diabetes; (4) Yuli Rob subjects were much older than the other two groups, which may also be part of the reason for higher BP and higher blood cholesterol, although in most cases our analysis was adjusted by age; and (5) there were higher blood sugar levels compared with other studies. ${ }^{20} 3233$ The reason for this needs further investigation.

In summary, because of the non-probability sampling design of the study and its low response rate, the results are unlikely to be conclusive. Nevertheless, our data indicate that epidemiological analyses in specific ethnic populations can identify unique CVD risk factors, which are likely to be very important in the development of tailored strategies for the prevention of CVD.

\section{Author affiliations}

${ }^{1}$ Department of epidemiology and biostatistics, Institute of Basic Medical Science, Chinese Academy of Medical Sciences and School of Basic Medicine, Peking Union Medical College, Beijing, China

${ }^{2}$ First Affiliated Hospital of Xinjiang Medical University, Urumqi, China ${ }^{3}$ People's General Hospital of Xinjiang Uyghur Autonomous Region, Urumqi, China

${ }^{4}$ Department of Brain Protection and Plasticity, Institute of Basic Medical Sciences, Beijing, China

Contributors Dr JJ was responsible for statistical analysis and drafting of the manuscript; Drs MW, AS, MN, PZ, were responsible for study filed and medical examination; Dr M was responsible for administrative, technical or 
material support; Dr GS took responsibility for critical revision of the manuscript and lab analysis; FL and FC contributed to lab analysis; Dr FX and XT had full access to all of the data in the study and the integrity of the data and the accuracy of the data analysis; $\mathrm{Dr}$ ZC and CQ contributed to the study concept and design, practice and guiding of the whole project. All authors have read and approved the final manuscript.

Funding This study was supported by Chinese Board of New York, Inc (CMB:96-657), The mega-projects of Science Research for the 11th Five-year Plan (2006BAll19B07), National Basic Research programme (973 Programme, 2006CB504103) and National Key Laboratory Special Fund (2060204).

Competing interests None.

Provenance and peer review Not commissioned; externally peer reviewed.

Data sharing statement No additional data are available.

\section{REFERENCES}

1. Zhou B, Wu Y, Yang J, et al. Overweight is an independent risk factor for cardiovascular disease in Chinese populations. Obes Rev 2003;3:147-56.

2. Gu D, Gupta A, Muntner P, et al. Prevalence of cardiovascular disease risk factor clustering among the adult population of China: results from the International Collaborative Study of Cardiovascular Disease in Asia. Circulation 2005;112:658-65.

3. Yu SZ, Shen HB. The status of coronary heart disease in China and other countries and the strategy for its prevention (Review). Chin $J$ Epidemiol (in Chinese) 1998;19:304-6.

4. Reddy KS, Yusuf S. Emerging epidemic of cardiovascular disease in developing countries. Circulation 1998;97:596-601.

5. Yusuf S, Reddy S, Ounpuu S, et al. Global burden of cardiovascular diseases part I: general considerations, the epidemiologic transition, risk factors, and impact of urbanization. Circulation 2001;104:2746-53.

6. Yu Z, Nissinen A, Vartiainen E, et al. Association between socioeconomic status and cardiovascular risk factors in an urban population in China. Bull World Health Organ 2000;78:1296-305.

7. Yang W, Lu J, Weng J, et al. Prevalence of diabetes among men and women in China. N Engl J Med 2010;362:1090-101.

8. Liu L, Ikeda K, Chen M, et al. Obesity, emerging risk in China: trend of increasing prevalence of obesity and its association with hypertension and hypercholesterolaemia among the Chinese. Clin Exp Pharmacol Physiol 2004;31(Suppl 2):S8-10.

9. Zhang $\mathrm{X}$, Shu XO, Gao YT, et al. Soy food consumption is associated with lower risk of coronary heart. J Nutr 2003;133:2874-8.

10. Lee J, Heng D, Chia KS, et al. Risk factors and incident coronary heart disease, in Chinese, Malay and Asian Indian males: the Singapore Cardiovascular Cohort Study. Int J Epidemiol 2001;30:983-8.

11. Aucott L, Rothnie H, McIntyre L, et al. Long-term weight loss from lifestyle intervention benefits blood pressure? Hypertension 2009;54:756-62.

12. Schillaci G, Pasqualini L, Vaudo G, et al. Effect of body weight changes on 24-hour blood pressure and left ventricular mass in hypertension: a 4-year follow-up. Am J Hypertens 2003;16:634-9.

13. Vasan RS, Larson MG, Leip EP, et al. Impact of high-normal blood pressure on the risk of cardiovascular disease. $N$ Engl $J$ Med 2001;345:1291-7.

14. Intersalt Cooperative Research Group. Intersalt: an international study of electrolyte excretion and blood pressure: results for 24 hour urinary sodium and potassium excretion. BMJ 1988;297:319-28.
15. Liu JY. Analysis of the construction of age and sex in Uyghur Population, Xingjiang. J Xinjiang Vocational Univ (in Chinese) 2003;11:7-11.

16. Ray KK, Cannon CP, Cairns R, et al. Prognostic utility of ApoBAI, total cholesterol/HDL, non-HDL cholesterol, or hs-CRP as predictors of clinical risk in patients receiving statin therapy after acute coronary syndromes: results from PROVE IT-TIMI 22. Arterioscler Thromb Vasc Biol 2009;29:424-30.

17. Lemieux I, Lamarche $\mathrm{B}$, Couillard $\mathrm{C}$, et al. Total cholesterol/HDL cholesterol ratio vs LDL cholesterol/HDL cholesterol ratio as indices of ischemic heart disease risk in men: the Quebec cardiovascular study. Arch Intern Med 2001;161:2685-92.

18. Yan W, Chen S, Huang J, et al. Polymorphisms in PLIN and hypertension combined with obesity and lipid profiles in Han Chinese. Obes Res 2004;12:1733-7.

19. Wang $X$, Fan Z, Huang J, et al. Extensive association analysis between polymorphisms of PON gene cluster with coronary heart disease in Chinese Han population. Arterioscler Thromb Vasc Biol 2003;23:328-34.

20. Yan W, Gu D, Yang X, et al. High-density lipoprotein cholesterol levels increase with age, body mass index, blood pressure and fasting blood glucose in a rural Uygur population in China. $J$ Hypertens 2005;23:1985-9.

21. Wang B, Wang CX, Wang DY, et al. Prevalence and risk factors of essential hypertension in Yi people in Sichuan province, China. Chin J Pub Health 2010;26:472-3.

22. Sizlan A, Ogur R, Ozer M, et al. Blood pressure changes in young male subjects exposed to a median altitude. Clin Auton Res 2008;18:84-9.

23. Arslan S, Arslan N, Soylu A, et al. High altitude and blood pressure in children. Yale J Biol Med 2003;76:145-8.

24. Hanna JM. Climate, altitude, and blood pressure. Hum Biol 1999;71:553-82.

25. Al-Tamer YY, Al-Hayali JM, Al-Ramadhan EA. Seasonality of hypertension. J Clin Hypertens 2008;10:125-9.

26. Ansa VO, Ekott JU, Essien IO, et al. Seasonal variation in admission for heart failure, hypertension and stroke in Uyo South-Eastern Nigeria. Ann Afr Med 2008;7:62-6.

27. Kinra S, Bowen LJ, Lyngdoh T, et al. Sociodemographic patterning of non-communicable disease risk factors in rural India: a cross sectional study. BMJ 2010;341:c4974.

28. Montalvo G, Avanzini F, Anselmi M, et al. Diagnostic evaluation of people with hypertension in low income country: cohort study of "essential" method of risk stratification. $B M$ 2008;337:a1387.

29. Beaglehole R, Yach D. Globalisation and the prevention and control of non-communicable disease: the neglected chronic diseases of adults. Lancet 2003;362:903-8.

30. Coutinho M, Gerstein HC, Wang Y, et al. The relationship between glucose and incidence cardiovascular events: a metaregression analysis of published data from 20 studies of 95783 individuals followed for 12.4 years. Diabetes Care 1999;22:233-40.

31. Gerstein HC, Pais P, Pogue J, et al. Relationship of glucose and insulin levels to the risk of myocardial infarction: a case-control study. J Am Coll Cardiol 1999;33:612-19.

32. Tao Y, Mao X, Xie Z, et al. The prevalence of type 2 diabetes and hypertension in Uygur and Kazak populations. Cardiovasc Toxicol 2008;8:155-9.

33. Zhao L, Wang K, Guo YY, et al. Epidemiology study on hypertension in Boretala Mongol Autonomous Prefecture of Xinjiang. Chin J Hypertension (in Chinese) 2006;14:214-18. 